\title{
OPTIMASI PENYEWAAN DUMP TRUCK PADA PROYEK X DI WILAYAH JAKARTA DENGAN METODE LINEAR PROGRAMMING
}

\author{
Setiadi Handokoe ${ }^{1}$ dan Iwan B. Santoso ${ }^{2}$ \\ ${ }^{1}$ Program Studi Sarjana Teknik Sipil Universitas Tarumanagara, Jl. Letjen S Parman No.1, Jakarta \\ Email: handokoes@gmail.com \\ ${ }^{2}$ Program Studi Sarjana Teknik Sipil, Universitas Tarumanagara, Jl. Letjen S Parman No.1 Jakarta \\ Email: iwsantoso@hotmail.com
}

\begin{abstract}
ABSTRAK
Saat ini, pembangunan gedung di wilayah Jakarta terus dilakukan karena pertumbuhan ekonomi yang begitu cepat. Dalam perkerjaan pembangunan, diperlukan pekerjaan penggalian tanah. Tanah yang digali perlu untuk dipindahkan ke tempat lain untuk tidak menggangu area lahan pekerjaaan. Salah satu alat yang dibutuhkan untuk memindahkan tanah dari satu tempat ke tempat lain yang berjarak jauh adalah Dump Truck. Studi ini menangani masalah pengoptimalan penyewaan Dump Truck untuk meminimalkan biaya sewa Dump Truck. Metode Linear Programming merupakan metode yang digunakan dalam mengoptimalkan penyewaan Dump Truck. Metode Linear Programming terdiri dari decision variabel, objective function, dan constraint. Penelitian menggunakan 10 perusahaan Dump Truck yang disewa untuk mengangkut tanah dengan 2 tipe kapasitas yang berbeda. Data tersebut diolah dengan menggunakan program LINGO untuk menentukan banyak Dump Truck yang digunakan dari perusahaan - perusahaan dan didapat harga termurah yang perlu dikeluarkan adalah Rp 3.183.989.000,-. Program LINGO ini membuktikan bahwa biaya yang diperoleh lebih efisien dengan mrnggunakan metode Linear Programming dibandingkan dengan cara memesan secara aktual di lapangan.
\end{abstract}

Kata kunci: Dump Truck, Linear Programming, Pengoptimalan, LINGO

\section{PENDAHULUAN}

\section{Latar Belakang}

Pembangunan di Indonesia terutama di wilayah Jakarta berkembang sangat pesat. Sebagian besar pembangunan tersebut menggunakan alat berat. Alat berat adalah faktor penting di dalam proyek-proyek konstruksi. Tujuan dari penggunaan alat berat adalah untuk memudahkan dalam mengerjakan pekerjaan sehingga hasil yang diharapkan dapat tercapai dengan lebih mudah pada waktu yang relatif lebih singkat (Kholil, 2012).

Seiring dengan berjalannya waktu, bidang transportasi mengalami banyak evolusi dari zaman ke zaman baik dari transportasi darat hingga udara. Alat transportasi darat yang memungkinkan pengendara dapat mengendarai alat transportasi tersebut secara mekanik seperti sepeda motor, mobil, bus, truk, dan alat transportasi darat lainnya. Salah satu alat transportasi darat yang berfungsi mendistribusikan barang ataupun jasa yaitu Truck. Truck dilengkapi dengan Dump (bak) untuk menampung muatan yang besar. Dump biasanya berbahan dasar kayu atau besi yang kuat untuk menampung banyaknya muatan (Beliana, et al, 2010).

Kenapa harus Dump Truck? Sepenting apakah alat berat ini? Dump Truck merupakan jenis alat berat yang sangat penting perannya dalam pertambangan, konstruksi, atau yang lainnya untuk efisiensi pekerjaan. Tanpa adanya alat berat ini, pemindahan tanah akan semakin sulit untuk dilakukan karena terbatasnya lahan pekerjaan untuk meletakkan tanah - tanah yang sudah digali. Banyak proyek - proyek yang mengunakan alat Dump Truck ini untuk mengangkut material dari sumbernya dan diangkut menuju tempat tertentu tersebut.

Untuk mempercepat pengerjaan, kontraktor bersikap untuk menyewa jasa Dump Truck kepada lebih dari 1 perusahaan. Hal ini dilakukan agar tidak menghambat pengerjaan galian yang harus diselesaikan untuk memperoleh volume yang sudah diharapkan agar tidak terjadi keterlambatan pada pekerjaan berikutnya.

Metode Linear Programming merupakan metode matematik dalam mengalokasikan sumber daya yang terbatas untuk mencapai suatu tujuan seperti memaksimumkan keuntungan dan meminimumkan biaya program untuk mendapatkan hasil yang efisien. Dengan demikian, penggunaan metode ini diharapkan agar kontraktor dapat menentukan penyewaan Dump Truck yang tepat sehingga dapat meminimumkan biaya penyewaan. 


\section{Identifikasi Masalah}

Berdasarkan pembahasan pada bagian sebelumnya, masalah yang akan dijadikan bahan penelitian yaitu besarnya biaya yang perlu dikeluarkan untuk penyewaan Dump Truck pada proyek X.

\section{Rumusan Masalah}

Masalah yang ingin dipecahkan untuk melakukan optimasi adalah berapa jumlah Dump Truck yang akan disewa agar dapat mencapai target pemindahan volume tanah dengan biaya yang minimum.

\section{Tujuan Penelitian}

Berdasarkan pembahasan dari latar belakang dan rumusan masalah pada bagian sebelumnya, maka tujuan dari dilakukan penelelitian ini adalah :

1. Mengetahui jumlah Dump Truck yang digunakan dalam pekerjaan pemindahan tanah dengan metode linear programming.

2. Mengetahui biaya sewa alat yang dihasilkan dari penggunaan Dump Truck.

\section{Batasan Penelitian}

Agar penelitian ini lebih terarah, maka ditetapkan beberapa batasan diantaranya :

1. Metode perhitungan yang digunakan adalah linear programming dengan program LINGO.

2. Penelitian dilakukan pada proyek X yang berada di wilayah Jakarta

3. Pengerjaan yang diteliti yaitu penyewaan Dump Truck dari proyek X agar diperoleh biaya yang minimum

\section{TINJAUAN PUSTAKA}

\section{Dump Truck}

Menurut Maulidawati (2014), pengertian Dump Truck dilihat dari sisi teknik sipil adalah kendaraan yang digunakan untuk mengangkut bahan material seperti pasir, kerikil atau tanah untuk keperluan konstruksi. Isi muatannya diisikan oleh alat pemuat seperti backhoe, sedangkan untuk membongkar muatannya alat berat ini dapat bekerja sendiri dengan mengangkat bagian bak dengan menggunakan teknologi hidrolik. Dump Truck dilengkapi dengan bak terbuka yang dioperasikan dengan bantuan hidrolik pada bagian depan dari bak itu agar bisa diangkat keatas dan bagian belakang bak yang berfungsi sebagai engsel atau sumbu putar sehingga memungkinkan material yang diangkut bisa turun ke tempat yang diinginkan. Dump Truck biasa digunakan dalam industri pembangunan untuk memindahkan material hasil puing proyek ataupun material tanah. Dump Truck sangatlah efisien untuk pengangkutan jarak jauh

\section{Klasifikasi Dump Truck}

Menurut Maulidawati (2014), Dump Truck dapat diklasifikasikan berdasarkan faktor dan cara kerja yaitu sebagai berikut :

1. Ukuran, tipe mesin dan bahan bakar.

2. Jumlah roda, as dan cara penyetiran.

3. Metode pembongkaran muatan.

4. Kapasitas.

5. Sistem pembongkaran

Menurut Rostiyanti (2008), Dump Truck terdapat tiga jenis berdasarkan metode pembongkarannya yaitu sebagai berikut :

\section{Rear Dump}

Rear Dump merupakan jenis Dump Truck yang memiliki cara pengosongan bak yang mana muatannya dibuang kebelakang dengan menggunakan hidraulik. Rear Dump terdiri dari dua jenis, yaitu Rear Dump Truck dan Rear Dump Tractor Wagon. Dari semua jenis truk, Rear Dump Truck adalah alat yang paling sering dipakai. Truk mempunyai kelebihan dibandingkan dengan wagon karena truk lebih kuat jika harus bergerak pada jalan menanjak. Cara kerja pembongkaran alat tipe ini adalah material dibongkar dengan cara menaikan bak bagian depan dengan sistem hidrolis. Ukuran bak truk jenis ini berkisar antara 25 sampai 250 ton. 


\section{Side Dump Truck}

Side Dump Truck merupakan jenis Dump Truck yang mengeluarkan material yang diangkutnya dengan menaikkan salah satu sisi bak ke samping. Saat pembongkaran material, perlu diperhatikannya distribusi material dalam bak. Karena kelebihan material pada salah satu sisi dapat menyebabkan terjadinya jungkir pada saat pembongkaran material. Pada kondisi dimana pembongkaran muatan dilakukan pada tempat yang sempit dan panjang, maka pemakaian Side Dump Truck merupakan pilihan yang tepat untuk digunakan.

3. Bottom Dump Truck

Bottom Dump Truck adalah semitrailer. Material yang diangkut oleh Bottom - Dump Tractor - Wagon dikeluarkan melalui bagian bawah bak yang dapat dibuka di tengah-tengahnya. Pintu bak adalah sisi bagian bawah memanjang dari depan ke belakang. Pintu - pintu tersebut digerakkan secara hidrolis. Bottom - Dump Tractor - Wagon umumnya mengangkut material lepas seperti pasir, kerikil, batuan sedimen, lempung keras, dan lain- lain. Pembongkaran material dilakukan pada saat kendaraan bergerak. Kelandaian permukaan di mana alat tersebut digunakan sebaiknya kurang dari 5\% karena bentuk dari alat tersebut tidak memungkinkan untuk daerah yang terjal dimana pembongkaran muatan dilakukan pada tempat yang sempit dan panjang maka pemakaian truk jenis ini merupakan pilihan yang tepat.

\section{Sifat Kembang Susut Tanah}

Volume dan kerapatan tanah secara umum mengalami perubahan-perubahan yang cukup besar apabila tanah itu digali, diangkut, diletakan, dan dipadatkan. Karena adanya perubahan volume pada kondisi tersebut, maka perlu diketahui dan ditetapkan adanya volume ditempat aslinya, dalam keadaaan lepas dan setelah dipadatkan, yang dimaksud dengan kembang susut tanah adalah perubahan baik berupa penambahan atau pengurangan volume tanah setelah diolah atau diubah dari bentuk asalnya. Volume pekerjaan tanah umumnya diukur dalam tiga kondisi:

1. Kondisi asli (Bank Cubic Meter/BCM), yaitu keadaan tanah yang masih sesuai dengan kondisi asli alamnya. Dalam keadaan ini butiran - butiran tanah masih terkonsolidasi dengan baik.

2. Kondisi lepas (Loose Cubic Meter/LCM), yaitu kondisi tanah sesudah mengalami gangguan atau telah tergali, misalnya keadaan tanah didepan dozer blade di atas Dump Truck dan di dalam bucket. Tanah yang telah tergali dari tempat asalnya ini akan mengalami perubahan volume, yaitu mengalami pengembangan tergantung dari jenis tanahnya seperti pada tabel 1 . Hal ini diakibatkan oleh adanya penambahan rongga udara butir-butir tanah, sehingga volumenya menjadi besar. Besarnya penambahan volume tergantung dari faktor kembang tanah (swelling factor) yang besarnya dipengaruhi oleh jenis tanah. Volume dalam keadaan lepas dapat dihitung dengan persamaan sebagai berikut:

$\mathrm{LCM}=\mathrm{BCM}+(\%$ SWELL $\times \mathrm{BCM})$

Dengan LCM $=$ Volume dalam kondisi lepas $\left(\mathrm{m}^{3}\right)$, BCM $=$ Volume dalam kondisi asli $\left(\mathrm{m}^{3}\right)$ dan $\operatorname{SWELL}=$ Faktor kembang tanah $(\%)$

Tabel 1. Faktor kembang pada beberapa jenis tanah

\begin{tabular}{|c|c|}
\hline Jenis Tanah & Faktor SWELL \\
\hline Pasir & $5-10 \%$ \\
\hline Tanah Permukaan (Top Soil) & $10-25 \%$ \\
\hline Tanah Biasa & $20-45 \%$ \\
\hline Lempung (Clay) & $30-50 \%$ \\
\hline Batu & $50-60 \%$ \\
\hline
\end{tabular}

3. Kondisi padat (Solid Measure/SM), yaitu kondisi tanah setelah ditimbun kembali dan diadakan usaha pemadatan. Perubahan volume pada keadaan ini terjadi karena adanya penyusutan rongga udara diantara partikel-partikel tanah tersebut. Besarnya volume dalam keadaan padat tergantung dari jenis tanah.

\section{Program Linear (Linear Programming)}

Van Den Broek (2017) menyatakan program linear merupakan teknik yang fleksibel yang dapat diterapkan pada banyak masalah di dunia nyata. Keuntungan utama pemrograman linear adalah pemodelan masalah bagaimana kita menerjemahkan masalah optimasi ke program linear yang dapat diolah secara efisien, apa variabel keputusan yang akan kita gunakan untuk mengkodekan solusi dari masalah, dan bagaimana kita bisa menulis ulang kendala masalah pada persamaan linier. Menurut Garg, K. T. N. (2008), program linear adalah masalah memaksimalkan atau meminimalkan fungsi linear pada sejumlah batasan linear. Menurut Assauri (1980), pengertian program linear ialah suatu teknik perencanaan yang dengan menggunakan model matematika dengan tujuan untuk menemukan kombinasi - kombinasi produk yang terbaik didalam menyusun suatu alokasi sumber daya yang terbatas guna untuk 
mencapai tujuan yang digunakan dengan secara optimal. Secara umum, program linear dapat diartikan sebagai sebuah metode matematik untuk mencari pemecahan persoalan - persoalan yang timbul didalam perusahaan, yakni mencari keadaan yang optimal dengan cara memperhitungkan batasan yang ada. Menurut Taylor III, B. W. (1993), model dari linear programming mengandung beberapa komponen dan karakteristik yang umum. Model tersebut meliputi decision variables, objective function, dan constraints.

\section{METODOLOGI PENELITIAN}

\section{Tahapan - Tahapan Penelitian}

Pada penelitian ini, dilakukan tahapan penelitian dengan langkah - langkah sebagai berikut :

1. Melakukan penyesuaian mengenai data - data yang didapat dengan data yang diperlukan untuk analisis.

2. Melakukan peringkasan data - data yang dibutuhkan untuk mempermudah pembacaan data.

3. Menentukan variabel keputusan (decision variable) dan dinyatakan dalam bentuk simbol.

4. Membuat fungsi tujuan (objective function) yang ingin dicapai (maksimalisasi atau minimalisasi) berdasarkan variabel keputusan yang telah dibuat.

5. Menentukan kendala masalah yang terdapat dalam data dan menuliskan bentuk persamaan atau pertidaksamaan berdasarkan variabel keputusan yang ada.

6. Melakukan pengolahan data menggunakan metode linear programming dengan bantuan program LINGO

7. Melakukan analisis data dengan membandingkan hasil dari optimasi menggunakan linear programming berdasarkan data aktual yang didapat dari perusahaan untuk menunjukkan perhitungan mana yang lebih baik.

8. Menarik kesimpulan dan saran berdasarkan hasil analisis yang sudah dilakukan.

\section{Kerangka Berpikir}

Proses penelitian yang dilakukan dapat digambarkan melalui kerangka berpikir yang dapat dilihat pada Gambar 1

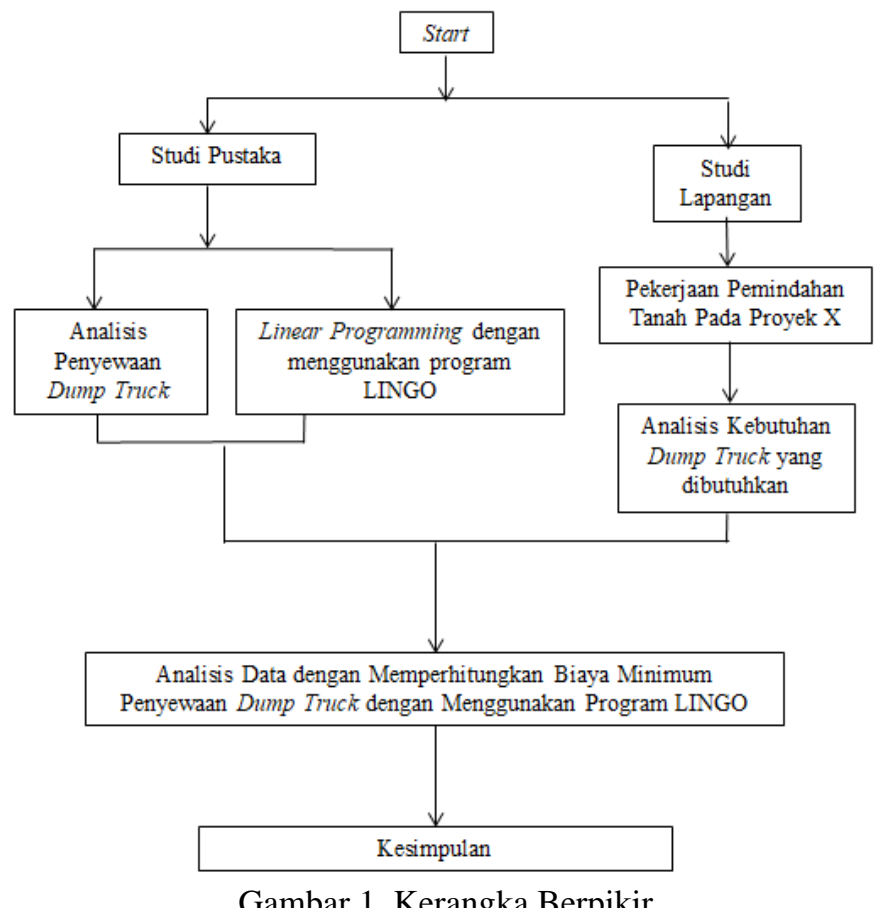

Gambar 1. Kerangka Berpikir

\section{HASIL DAN PEMBAHASAN}

\section{Perhitungan Biaya Penyewaan Dump Truck}

Biaya penyewaan adalah biaya yang digunakan untuk menyewa Dump truck dengan perhitungan banyaknya volume tanah yang ingin diangkut dan berapa banyak yang perlu disewa karena penyewaan dilakukan lebih dari 1 perusahaan Dump truck. Berikut ini adalah rincian harga penyewaan Dump truck dari tiap perusahaan : 
1. Perusahaan A $20 \mathrm{~m}^{3}=\mathrm{Rp} 250.000 /$ rit

2. Perusahaan A $24 \mathrm{~m}^{3}=\mathrm{Rp} 315.000 /$ rit

3. Perusahaan $\mathrm{B} 20 \mathrm{~m}^{3}=\mathrm{Rp} 250.000 / \mathrm{rit}$

4. Perusahaan B $24 \mathrm{~m}^{3}=\mathrm{Rp} 320.000 /$ rit

5. Perusahaan $\mathrm{C} 20 \mathrm{~m}^{3}=\mathrm{Rp} 275.000 /$ rit

6. Perusahaan C $24 \mathrm{~m}^{3}=\mathrm{Rp} 345.000 /$ rit

7. Perusahaan D $20 \mathrm{~m}^{3}=\mathrm{Rp} 275.000 /$ rit

8. Perusahaan D $24 \mathrm{~m}^{3}=\operatorname{Rp} 345.000 /$ rit

9. Perusahaan E $20 \mathrm{~m}^{3}=\mathrm{Rp} 285.000 / \mathrm{rit}$

10. Perusahaan E $24 \mathrm{~m}^{3}=\mathrm{Rp} 350.000 /$ rit
11. Perusahaan F $20 \mathrm{~m}^{3}=\mathrm{Rp} 285.000 /$ rit

12. Perusahaan F $24 \mathrm{~m}^{3}=\mathrm{Rp} 350.000 /$ rit

13. Perusahaan G $20 \mathrm{~m}^{3}=\mathrm{Rp} 250.000 / \mathrm{rit}$

14. Perusahaan G $24 \mathrm{~m}^{3}=\mathrm{Rp} 345.000 /$ rit

15. Perusahaan $\mathrm{H}_{20} \mathrm{~m}^{3}=\mathrm{Rp} 285.000 / \mathrm{rit}$

16. Perusahaan $\mathrm{H} 24 \mathrm{~m}^{3}=\mathrm{Rp} 350.000 /$ rit

17. Perusahaan $\mathrm{I} 20 \mathrm{~m}^{3}=\mathrm{Rp} 285.000 /$ rit

18. Perusahaan $\mathrm{I} 24 \mathrm{~m}^{3}=\mathrm{Rp} 350.000 / \mathrm{rit}$

19. Perusahaan $\mathrm{J} 20 \mathrm{~m}^{3}=\mathrm{Rp} 285.000 / \mathrm{rit}$

20. Perusahaan $\mathrm{J} 24 \mathrm{~m}^{3}=\mathrm{Rp} 350.000 /$ rit

\section{Perhitungan Biaya Kebutuhan Solar}

Biaya ini adalah biaya yang berasal dari lamanya penggunaan kendaraan selama digunakan. Perhitungan yang dilakukan untuk mendapatkan biaya ini adalah harga solar per liter dikali dengan konsumsi solar dikali dengan jumlah jam kerja per hari dikali jumlah hari. Berikut ini adalah rincian mengenai kebutuhan solar pada kendaraan Dump Truck :

Jarak yang ditempuh mobil Dump Truck dari proyek ke pembuangan $\pm 30 \mathrm{~km}$

Penggunaan untuk Dump Truck berkapasitas $20 \mathrm{~m} 3$ rata - rata 8 liter/jam

Penggunaan untuk Dump Truck berkapastias $24 \mathrm{~m} 3$ rata - rata 9 liter/jam

Harga solar per liter $=$ Rp $5.150 /$ liter

Biaya untuk kebutuhan solar Dump Truck berkapasitas $20 \mathrm{~m} 3$ :

Rp 5.150 /liter x 8 liter/jam x 10 jam = Rp 412.000

Biaya untuk kebutuhan solar Dump Truck berkapasitas $24 \mathrm{~m} 3$ :

Rp 5.150 /liter x 9 liter/jam x 10 jam = Rp 463.500

\section{Perhitungan Biaya Untuk Operator}

Biaya untuk operator per jam $=$ Rp $20.000 /$ jam

Maka, biaya operator untuk 1 mobil adalah:

Rp $20.000 /$ jam x 10 jam = Rp 200.000

\section{Perhitungan Biaya Total Penyewaan Dump Truck}

Jika ditotal keseluruhan biaya yang dikeluarkan, maka rincian total harga penyewaan Dump Truck dari tiap perusahaan adalah sebagai berikut :

1. Perusahaan A $20 \mathrm{~m}^{3}=\mathrm{Rp} 862.000$

2. Perusahaan A $24 \mathrm{~m}^{3}=\mathrm{Rp} 978.500$

3. Perusahaan $B 20 \mathrm{~m}^{3}=\mathrm{Rp} 862.000$

4. Perusahaan B $24 \mathrm{~m}^{3}=\mathrm{Rp} 983.500$

5. Perusahaan $\mathrm{C} 20 \mathrm{~m}^{3}=\mathrm{Rp} 887.000$

6. Perusahaan C $24 \mathrm{~m}^{3}=\mathrm{Rp} 1.008 .500$

7. Perusahaan D $20 \mathrm{~m}^{3}=\mathrm{Rp} 887.000$

8. Perusahaan D $24 \mathrm{~m}^{3}=\mathrm{Rp} 1.008 .500$

9. Perusahaan E $20 \mathrm{~m}^{3}=\mathrm{Rp} 897.000$

10. Perusahaan E $24 \mathrm{~m}^{3}=\mathrm{Rp} 1.013 .500$
11. Perusahaan F $20 \mathrm{~m}^{3}=\mathrm{Rp} 897.000$

12. Perusahaan F $24 \mathrm{~m}^{3}=\mathrm{Rp} 1.013 .500$

13. Perusahaan G $20 \mathrm{~m}^{3}=\operatorname{Rp} 862.000$

14. Perusahaan G $24 \mathrm{~m}^{3}=\mathrm{Rp} 1.008 .500$

15. Perusahaan $\mathrm{H} 20 \mathrm{~m}^{3}=\mathrm{Rp} 897.000$

16. Perusahaan $\mathrm{H} 24 \mathrm{~m}^{3}=\mathrm{Rp} 1.013 .500$

17. Perusahaan $\mathrm{I} 20 \mathrm{~m}^{3} \quad=\mathrm{Rp} 897.000$

18. Perusahaan I $24 \mathrm{~m}^{3} \quad=\mathrm{Rp} 1.013 .500$

19. Perusahaan $\mathrm{J} 20 \mathrm{~m}^{3}=\mathrm{Rp} 897.000$

20. Perusahaan $\mathrm{J} 24 \mathrm{~m}^{3}=\mathrm{Rp} 1.013 .500$

\section{Pemodelan Linear Programming}

Berikut ini merupakan pemodelan penyewaan Dump Truck dalam bentuk linear programming :

\section{Decision Variabel}

Berikut adalah decision variable yang digunakan untuk penyewaan Dump Truck tiap perusahaan sebagai berikut :
a. $\quad \mathrm{DA}_{1-121}=$ Jumlah Dump Truck yang dibutuhkan dari perusahaan A kapasitas $20 \mathrm{~m}^{3}$ minggu ke $1-12$
b. $\mathrm{DA}_{1-122}=$ Jumlah Dump Truck yang dibutuhkan dari perusahaan A kapasitas $24 \mathrm{~m}^{3}$ minggu ke $1-12$
c. $\mathrm{DB}_{1-121}=$ Jumlah Dump Truck yang dibutuhkan dari perusahaan B kapasitas $20 \mathrm{~m}^{3}$ minggu ke $1-12$
d. $\quad \mathrm{DB}_{1-122}=$ Jumlah Dump Truck yang dibutuhkan dari perusahaan B kapasitas $24 \mathrm{~m}^{3}$ minggu ke $1-12$
e. $\quad \mathrm{DC}_{1-121}=$ Jumlah Dump Truck yang dibutuhkan dari perusahaan C kapasitas $20 \mathrm{~m}^{3}$ minggu ke $1-12$
f. $\quad \mathrm{DC}_{1-122}=$ Jumlah Dump Truck yang dibutuhkan dari perusahaan C kapasitas $24 \mathrm{~m}^{3}$ minggu ke $1-12$ 
g. $\quad \mathrm{DD}_{1-121}=$ Jumlah Dump Truck yang dibutuhkan dari perusahaan D kapasitas $20 \mathrm{~m}^{3}$ minggu ke $1-12$

h. $\mathrm{DD}_{1-122}=$ Jumlah Dump Truck yang dibutuhkan dari perusahaan D kapasitas $24 \mathrm{~m}^{3}$ minggu ke $1-12$

i. $\quad \mathrm{DE}_{1-121}=$ Jumlah Dump Truck yang dibutuhkan dari perusahaan E kapasitas $20 \mathrm{~m}^{3}$ minggu ke 1- 12

j. $\quad \mathrm{DE}_{1-122}=$ Jumlah Dump Truck yang dibutuhkan dari perusahaan E kapasitas $24 \mathrm{~m}^{3}$ minggu ke $1-12$

k. $\quad \mathrm{DF}_{1-121}=$ Jumlah Dump Truck yang dibutuhkan dari perusahaan F kapasitas $20 \mathrm{~m}^{3}$ minggu ke $1-12$

1. $\mathrm{DF}_{1-122}=$ Jumlah Dump Truck yang dibutuhkan dari perusahaan F kapasitas $24 \mathrm{~m}^{3}$ minggu ke $1-12$

m. $\quad \mathrm{DG}_{1-121}=$ Jumlah Dump Truck yang dibutuhkan dari perusahaan G kapasitas $20 \mathrm{~m}^{3}$ minggu ke $1-12$

n. $\quad \mathrm{DG}_{1-122}=$ Jumlah Dump Truck yang dibutuhkan dari perusahaan G kapasitas $24 \mathrm{~m}^{3}$ minggu ke $1-12$

o. $\quad \mathrm{DH}_{1-121}=$ Jumlah Dump Truck yang dibutuhkan dari perusahaan H kapasitas $20 \mathrm{~m}^{3}$ minggu ke $1-12$

p. $\quad \mathrm{DH}_{1-122}=$ Jumlah Dump Truck yang dibutuhkan dari perusahaan H kapasitas $24 \mathrm{~m}^{3}$ minggu ke $1-12$

q. DI $_{1-121}=$ Jumlah Dump Truck yang dibutuhkan dari perusahaan I kapasitas $20 \mathrm{~m}^{3}$ minggu ke $1-12$

r. $\quad \mathrm{DI}_{1-122}$ = Jumlah Dump Truck yang dibutuhkan dari perusahaan I kapasitas $24 \mathrm{~m}^{3}$ minggu ke $1-12$

s. $\quad$ DJ $_{1-121}=$ Jumlah Dump Truck yang dibutuhkan dari perusahaan J kapasitas $20 \mathrm{~m}^{3}$ minggu ke $1-12$

t. $\quad \mathrm{DJ}_{1-122}=$ Jumlah Dump Truck yang dibutuhkan dari perusahaan J kapasitas $24 \mathrm{~m}^{3}$ minggu ke $1-12$

2. Objective Function

Objective Function dari penelitian ini adalah untuk meminimalkan biaya penyewaan Dump Truck dengan memperhitungkan jumlah volume tanah yang akan diangkut, kapasitas mobil Dump Truck yang tersedia, dan waktu kerja Dump Truck yang beroperasi

Minimize $\mathrm{Z}=(862 \times \mathrm{DA} 1-121)+(978.5 \times \mathrm{DA} 1-122)+(862 \times \mathrm{DB} 1-121)+(983.5 \times \mathrm{DB} 1-122)+(887 \times$ $\mathrm{DC} 1-121)+(1008.5 \times \mathrm{DC} 1-122)+(887 \times \mathrm{DD} 1-121)+(1008.5 \times \mathrm{DD} 1-122)+(897 \times \mathrm{DE} 1-121)+(1013.5 \times$ $\mathrm{DE} 1-122)+(897 \times \mathrm{DF} 1-121)+(1013.5 \times \mathrm{DF} 1-122)+(862 \times \mathrm{DG} 1-121)+(1008.5 \times \mathrm{DG} 1-122)+(897 \times$ DH1-12 1) +(1013.5 x DH1-12 2) + (897 x DI1-12 1) +(1013.5 x DI1-12 2) + (897 x DJ1-12 1) + (1013.5 x DJ1-12 1)

\section{Constraint}

Constraint yang dibutuhkan agar linear programming mendapatkan hasil yang direncanakan adalah sebagai berikut:

Constraint untuk volume tanah yang diangkut

a. $20 \mathrm{DA} 11+24 \mathrm{DA} 12+20 \mathrm{DB} 11+24 \mathrm{DB} 12+20 \mathrm{DC} 11+24 \mathrm{DC} 12+20 \mathrm{DD} 11+24 \mathrm{DD} 12+20$ $\mathrm{DE} 11$ + $24 \mathrm{DE} 12$ + $20 \mathrm{DF} 11$ + $24 \mathrm{DF} 12$ + 20 DG11 + $24 \mathrm{DG} 12$ + $20 \mathrm{DH} 11$ + $24 \mathrm{DH} 12$ + 20 DI11 + $24 \mathrm{DI} 12+20 \mathrm{DJ} 11+24 \mathrm{DJ} 12 \geq 6420$

b. $20 \mathrm{DA} 21+24 \mathrm{DA} 22+20 \mathrm{DB} 21+24 \mathrm{DB} 22+20 \mathrm{DC} 21+24 \mathrm{DC} 22+20 \mathrm{DD} 21+24 \mathrm{DD} 22+20$ $\mathrm{DE} 21+24 \mathrm{DE} 22$ + $20 \mathrm{DF} 21+24 \mathrm{DF} 22+20 \mathrm{DG} 21+24 \mathrm{DG} 22+20 \mathrm{DH} 21+24 \mathrm{DH} 22+20 \mathrm{DI} 21+$ $24 \mathrm{DI} 22+20 \mathrm{DJ} 21+24 \mathrm{DJ} 22 \geq 6420$

c. $20 \mathrm{DA} 31+24 \mathrm{DA} 32+20 \mathrm{DB} 31+24 \mathrm{DB} 32+20 \mathrm{DC} 31+24 \mathrm{DC} 32+20 \mathrm{DD} 31+24 \mathrm{DD} 32+20$ $\mathrm{DE} 31+24 \mathrm{DE} 32$ + $20 \mathrm{DF} 31+24 \mathrm{DF} 32$ + $20 \mathrm{DG} 31+24 \mathrm{DG} 32$ + $20 \mathrm{DH} 31+24 \mathrm{DH} 32+20 \mathrm{DI} 31+$ $24 \mathrm{DI} 32+20 \mathrm{DJ} 31+24 \mathrm{DJ} 32 \geq 3210$

d. 20 DA41 + 24 DA42 + 20 DB41 + 24 DB42 + 20 DC41 + 24 DC42 + 20 DD41 + 24 DD42 + 20 $\mathrm{DE} 41+24 \mathrm{DE} 42$ + $20 \mathrm{DF} 41+24 \mathrm{DF} 42$ + 20 DG41 + 24 DG42 + $20 \mathrm{DH} 41+24 \mathrm{DH} 42+20 \mathrm{DI} 41+$ 24 DI42 + 20 DJ41 + 24 DJ42 $\geq 4200$

e. 20 DA51 + 24 DA52 + 20 DB51 + 24 DB52 + 20 DC51 + 24 DC52 + 20 DD51 + 24 DD52 + 20 DE51 + 24 DE52 + 20 DF51 + 24 DF52 + 20 DG51 + 24 DG52 + 20 DH51 + 24 DH52 + 20 DI51 + 24 DI52 + 20 DJ51 + 24 DJ52 $\geq 7490$

f. 20 DA61 + 24 DA62 + 20 DB61 + 24 DB62 + 20 DC61 + 24 DC62 + 20 DD61 + 24 DD62 + 20 DE61 + 24 DE62 + 20 DF61 + 24 DF62 + 20 DG61 + 24 DG62 + 20 DH61 + 24 DH62 + 20 DI61 + 24 DI62 + 20 DJ61 + 24 DJ62 $\geq 5350$

g. $20 \mathrm{DA} 71+24 \mathrm{DA} 72+20 \mathrm{DB} 71+24 \mathrm{DB} 72+20 \mathrm{DC} 71+24 \mathrm{DC} 72+20 \mathrm{DD} 71+24 \mathrm{DD} 72+20$ DE71 + 24 DE72 + 20 DF71 + 24 DF72 + 20 DG71 + 24 DG72 + 20 DH71 + 24 DH72 + 20 DI71 + $24 \mathrm{DI} 72+20 \mathrm{DJ} 71+24 \mathrm{DJ} 72 \geq 4280$

h. 20 DA81 + 24 DA82 + 20 DB81 + 24 DB82 + 20 DC81 + 24 DC82 + 20 DD81 + 24 DD82 + 20 $\mathrm{DE} 81+24 \mathrm{DE} 82$ + 20 DF81 + 24 DF82 + 20 DG81 + 24 DG82 + 20 DH81 + 24 DH82 + 20 DI81 + $24 \mathrm{DI} 82+20$ DJ81 + 24 DJ82 $\geq 5870$

i. 20 DA91 + 24 DA92 + 20 DB91 + 24 DB92 + 20 DC91 + 24 DC92 + 20 DD91 + 24 DD92 + 20 DE91 + 24 DE92 + 20 DF91 + 24 DF92 + 20 DG91 + 24 DG92 + 20 DH91 + 24 DH92 + 20 DI91 + 24 DI92 + 20 DJ91 + 24 DJ92 $\geq 8480$

j. $20 \mathrm{DA} 101+24 \mathrm{DA} 102+20 \mathrm{DB} 101+24 \mathrm{DB} 102+20 \mathrm{DC} 101+24 \mathrm{DC} 102+20 \mathrm{DD} 101+24 \mathrm{DD} 102$ + $20 \mathrm{DE} 101+24 \mathrm{DE} 102$ + $20 \mathrm{DF} 101+24 \mathrm{DF} 102$ + $20 \mathrm{DG} 101$ + $24 \mathrm{DG} 102$ + $20 \mathrm{DH} 101$ + $24 \mathrm{DH} 102$ + 20 DI101 + 24 DI102 + 20 DJ101 + 24 DJ102 $\geq 8480$ 
k. 20 DA111 + 24 DA112 + 20 DB111 + 24 DB112 + 20 DC111 + 24 DC112 + 20 DD111 + 24 DD112 + 20 DE111 + 24 DE112 + 20 DF111 + 24 DF112 + 20 DG111 + 24 DG112 + 20 DH111 + 24 DH112 + $20 \mathrm{DI} 111+24 \mathrm{DI} 112+20 \mathrm{DJ} 111+24 \mathrm{DJ} 112 \geq 8480$

1. $20 \mathrm{DA} 121+24 \mathrm{DA} 122+20 \mathrm{DB} 121+24 \mathrm{DB} 122+20 \mathrm{DC} 121+24 \mathrm{DC} 122+20 \mathrm{DD} 121+24 \mathrm{DD} 122$ + 20 DE121 + 24 DE122 + 20 DF121 + 24 DF122 + 20 DG121 + 24 DG122 + 20 DH121 + 24 DH122 + 20 DI121 + 24 DI122 + 20 DJ121 + 24 DJ122 $\geq 8480$

Constraint untuk jumlah Dump Truck yang tersedia

\begin{tabular}{|c|c|c|c|}
\hline DA11 $\leq 67$ & $\mathrm{DA} 21 \leq 80$ & DA31 $\leq 71$ & $\mathrm{DA} 41 \leq 73$ \\
\hline $\mathrm{DA} 12 \leq 116$ & DA22 $\leq 105$ & DA $32 \leq 67$ & DA42 $\leq 77$ \\
\hline $\mathrm{DB} 11=0$ & DB21 $=0$ & $\mathrm{DB} 31=0$ & DB41 $\leq 4$ \\
\hline $\mathrm{DB} 12=0$ & $\mathrm{DB} 22 \leq 46$ & $\mathrm{DB} 32=0$ & DB42 $\leq 24$ \\
\hline $\mathrm{DC} 11=0$ & $\mathrm{DC} 21=0$ & $\mathrm{DC} 31 \leq 3$ & $\mathrm{DC} 41=0$ \\
\hline $\mathrm{DC} 12=0$ & $\mathrm{DC} 22 \leq 31$ & $\mathrm{DC} 32 \leq 8$ & $\mathrm{DC} 42=0$ \\
\hline DD11 $=0$ & $\mathrm{DD} 21=0$ & $\mathrm{DD} 31=0$ & DD41 $=0$ \\
\hline DD12 $=0$ & DD22 $=0$ & DD32 $=0$ & DD42 $=0$ \\
\hline $\mathrm{DE} 11=0$ & $\mathrm{DE} 21=0$ & $\mathrm{DE} 31=0$ & $\mathrm{DE} 41=0$ \\
\hline $\mathrm{DE} 12=0$ & $\mathrm{DE} 22=0$ & $\mathrm{DE} 32=0$ & $\mathrm{DE} 42=0$ \\
\hline $\mathrm{DF} 11=0$ & $\mathrm{DF} 21=0$ & $\mathrm{DF} 31=0$ & DF41 $=0$ \\
\hline $\mathrm{DF} 12=0$ & DF $22 \leq 18$ & DF32 $=0$ & $\mathrm{DF} 42=0$ \\
\hline $\mathrm{DG} 11=0$ & $\mathrm{DG} 21=0$ & $\mathrm{DG} 31 \leq 3$ & $\mathrm{DG} 41=0$ \\
\hline DG12 $\leq 90$ & $\mathrm{DG} 22 \leq 32$ & DG $32 \leq 4$ & DG42 $\leq 4$ \\
\hline DH11 = 0 & $\mathrm{DH} 21=0$ & $\mathrm{DH} 31=0$ & DH41 = 0 \\
\hline DH12 $\leq 4$ & $\mathrm{DH} 22 \leq 14$ & $\mathrm{DH} 32 \leq 10$ & $\mathrm{DH} 42=0$ \\
\hline DI11 = 0 & $\mathrm{DI} 21=0$ & $\mathrm{DI} 31=0$ & DI41 = 0 \\
\hline DI1 $\leq 2$ & $\mathrm{DI} 22 \leq 1$ & $\mathrm{DI} 32=0$ & $\mathrm{DI} 42=0$ \\
\hline $\mathrm{DJ} 11=0$ & $\mathrm{DJ} 21=0$ & $\mathrm{DJ} 31=0$ & $\mathrm{DJ} 41=0$ \\
\hline $\mathrm{DJ} 12=0$ & $\mathrm{DJ} 22 \leq 5$ & $\mathrm{DJ} 32=0$ & $\mathrm{DJ} 42=0$ \\
\hline
\end{tabular}

\begin{tabular}{|c|c|c|c|}
\hline $\mathrm{DA} 51 \leq 180$ & $\mathrm{DA} 61 \leq 152$ & DA7 $71 \leq 139$ & $\mathrm{DA} 81 \leq 166$ \\
\hline DA52 $\leq 162$ & DA62 $\leq 97$ & DA $72 \leq 52$ & DA $82 \leq 78$ \\
\hline DB51 $=0$ & DB61 $=0$ & $\mathrm{DB} 71=0$ & $\mathrm{DB} 81=0$ \\
\hline DB52 $\leq 69$ & $\mathrm{DB} 62 \leq 9$ & $\mathrm{DB} 72=0$ & $\mathrm{DB} 82=0$ \\
\hline DC51 $=0$ & DC61 $=0$ & $\mathrm{DC} 71=0$ & $\mathrm{DC} 81=0$ \\
\hline DC52 $=0$ & DC62 $=0$ & $\mathrm{DC} 72=0$ & $\mathrm{DC} 82=0$ \\
\hline DD51 $=0$ & $\mathrm{DD} 61=0$ & DD71 $=0$ & DD81 $=0$ \\
\hline DD52 $=0$ & DD62 $=0$ & $\mathrm{DD} 72=0$ & DD82 $=0$ \\
\hline DE51 $=0$ & DE61 $=0$ & DE71 $=0$ & $\mathrm{DE} 81=0$ \\
\hline DE52 $=0$ & DE62 $=0$ & DE72 $=0$ & $\mathrm{DE} 82=0$ \\
\hline DF51 $=0$ & DF61 $=0$ & DF71 $=0$ & DF81 $=0$ \\
\hline DF52 $=0$ & DF62 $=0$ & $\mathrm{DF} 72=0$ & $\mathrm{DF} 82=0$ \\
\hline DG51 $=0$ & DG61 = 0 & DG71 $=0$ & DG81 $=0$ \\
\hline DG52 $\leq 11$ & DG62 $=0$ & DG $72 \leq 22$ & DG82 $\leq 35$ \\
\hline DH51 $=0$ & DH61 $=0$ & $\mathrm{DH} 71=0$ & DH81 = 0 \\
\hline DH52 $=0$ & DH62 $=0$ & $\mathrm{DH} 72=0$ & DH82 $=0$ \\
\hline $\mathrm{DI} 51=0$ & DI61 $=0$ & $\mathrm{DI} 71=0$ & $\mathrm{DI} 81=0$ \\
\hline DI52 $=0$ & DI62 $=0$ & $\mathrm{DI} 72=0$ & DI82 $=0$ \\
\hline DJ51 = 0 & DJ61 = 0 & $\mathrm{DJ} 71=0$ & DJ81 = 0 \\
\hline DJ52 $=0$ & DJ62 $=0$ & $\mathrm{DJ} 72=0$ & DJ82 $=0$ \\
\hline
\end{tabular}

$\begin{array}{llll}\text { DA91 } \leq 212 & \text { DA101 } \leq 236 & \text { DA11 } \leq 241 & \\ \text { DA92 } \leq 100 & \text { DA102 } \leq 97 & \text { DA112 } \leq 158 & \text { DA121 } \leq 227 \\ \text { DB91 }=0 & \text { DB101 }=0 & \text { DB111 }=0 & \text { DB121 } \leq 5 \\ \text { DB92 }=0 & \text { DB102 }=0 & \text { DB112 }=0 & \text { DB122 } \leq 87 \\ \text { DC91 }=0 & \text { DC101 }=0 & \text { DC111 }=0 & \text { DC121 }=0 \\ \text { DC92 }=0 & \text { DC102 }=0 & \text { DC112 }=0 & \text { DC122 } \leq 31 \\ \text { DD91 }=0 & \text { DD101 }=0 & \text { DD111 }=0 & \text { DD121 }=0 \\ \text { DD92 } \leq 9 & \text { DD102 }<61 & \text { DD112 } \leq 2 & \text { DD122 }=0 \\ \text { DE91 }=0 & \text { DE101 }=0 & \text { DE11 }=0 & \text { DE121 }=0\end{array}$




$\begin{array}{llll}\text { DE92 }=0 & \text { DE102 } \leq 6 & \text { DE112 }=0 & \text { DE122 } \leq 6 \\ \text { DF91 }=0 & \text { DF101 }=0 & \text { DF111 }=0 & \text { DF121 }=0 \\ \text { DF92 }=0 & \text { DF102 }=0 & \text { DF112 }=0 & \text { DF122 }=0 \\ \text { DG91 } \leq 21 & \text { DG101 }=0 & \text { DG111 }=0 & \text { DG121 } \leq 13 \\ \text { DG92 } \leq 89 & \text { DG102 } \leq 35 & \text { DG11 } \leq 8 & \text { DG122 } \leq 17 \\ \text { DH91 }=0 & \text { DH101 }=0 & \text { DH111 }=0 & \text { DH121 }=0 \\ \text { DH92 }=0 & \text { DH102 }=0 & \text { DH112 }=0 & \text { DH122 }=0 \\ \text { DI91 }=0 & \text { DI101 }=0 & \text { DI111 }=0 & \text { DI121 }=0 \\ \text { DI92 }=0 & \text { DI102 }=0 & \text { DI112 }=0 & \text { DI122 }=0 \\ \text { DJ91 }=0 & \text { DJ101 }=0 & \text { DJ111 }=0 & \text { DJ121 }=0 \\ \text { DJ92 }=0 & \text { DJ102 }=0 & \text { DJ112 }=0 & \text { DJ122 }=0\end{array}$

Constraint untuk waktu beroperasi

a. $15 \mathrm{DA} 11$ + $15 \mathrm{DA} 12$ + $15 \mathrm{DB} 11+15 \mathrm{DB} 12$ + $15 \mathrm{DC} 11+24 \mathrm{DC} 12$ + $15 \mathrm{DD} 11$ + $15 \mathrm{DD} 12$ + 15 $\mathrm{DE} 11$ + $15 \mathrm{DE} 12$ + $15 \mathrm{DF} 11$ + $15 \mathrm{DF} 12$ + $15 \mathrm{DG} 11$ + $15 \mathrm{DG} 12$ + $15 \mathrm{DH} 11$ + $15 \mathrm{DH} 12$ + $15 \mathrm{DI} 11$ $+24 \mathrm{DI} 12+15 \mathrm{DJ} 11+15 \mathrm{DJ} 12 \leq 5880$

b. $15 \mathrm{DA} 21+15 \mathrm{DA} 22+15 \mathrm{DB} 21+15 \mathrm{DB} 22+15 \mathrm{DC} 21+15 \mathrm{DC} 22+15 \mathrm{DD} 21+15 \mathrm{DD} 22+15$ $\mathrm{DE} 21+15 \mathrm{DE} 22$ + $15 \mathrm{DF} 21+15 \mathrm{DF} 22$ + $15 \mathrm{DG} 21$ + $15 \mathrm{DG} 22$ + $15 \mathrm{DH} 21+15 \mathrm{DH} 22$ + $15 \mathrm{DI} 21$ $+15 \mathrm{DI} 22+15 \mathrm{DJ} 21+15 \mathrm{DJ} 22 \leq 5880$

c. $15 \mathrm{DA} 31+15 \mathrm{DA} 32+15 \mathrm{DB} 31+15 \mathrm{DB} 32+15 \mathrm{DC} 31+15 \mathrm{DC} 32+15 \mathrm{DD} 31+15 \mathrm{DD} 32+15$ $\mathrm{DE} 31+15 \mathrm{DE} 32$ + $15 \mathrm{DF} 31$ + $15 \mathrm{DF} 32$ + $15 \mathrm{DG} 31$ + $15 \mathrm{DG} 32$ + $15 \mathrm{DH} 31$ + $15 \mathrm{DH} 32$ + $15 \mathrm{DI} 31$ $+15 \mathrm{DI} 32+15 \mathrm{DJ} 31+15 \mathrm{DJ} 32 \leq 5880$

d. $15 \mathrm{DA} 41+15 \mathrm{DA} 42+15 \mathrm{DB} 41+15 \mathrm{DB} 42+15 \mathrm{DC} 41+15 \mathrm{DC} 42+15 \mathrm{DD} 41+15 \mathrm{DD} 42+15$ DE41 + 15 DE42 + 15 DF41 + 15 DF42 + 15 DG41 + 15 DG42 + 15 DH41 + 15 DH42 + 15 DI41 +15 DI42 + 15 DJ41 + 15 DJ42 $\leq 5880$

e. $15 \mathrm{DA} 51+15 \mathrm{DA} 52$ + $15 \mathrm{DB} 51+15 \mathrm{DB} 52+15 \mathrm{DC} 51+15 \mathrm{DC} 52+15 \mathrm{DD} 51+15 \mathrm{DD} 52+15$ DE51 + 15 DE52 + 15 DF51 + 15 DF52 + 15 DG51 + 15 DG52 + 15 DH51 + 15 DH52 + 15 DI51 +15 DI52 + 15 DJ51 + 15 DJ52 $\leq 5880$

f. 15 DA61 + 15 DA62 + 15 DB61 + 15 DB62 + 15 DC61 + 15 DC62 + 15 DD61 + 15 DD62 + 15 DE61 + 15 DE62 + 15 DF61 + 15 DF62 + 15 DG61 + 15 DG62 + 15 DH61 + 15 DH62 + 15 DI61 +15 DI62 + 15 DJ61 + 15 DJ62 $\leq 5880$

g. $15 \mathrm{DA} 71+15 \mathrm{DA} 72+15 \mathrm{DB} 71+15 \mathrm{DB} 72+15 \mathrm{DC} 71+15 \mathrm{DC} 72+15 \mathrm{DD} 71+15 \mathrm{DD} 72+15$ DE71 + 15 DE72 + 15 DF71 + 15 DF72 + 15 DG71 + 15 DG72 + 15 DH71 + 15 DH72 + 15 DI71 +15 DI72 + 15 DJ71 + 15 DJ72 $\leq 5880$

h. $15 \mathrm{DA} 81+15 \mathrm{DA} 82+15 \mathrm{DB} 81+15 \mathrm{DB} 82+15 \mathrm{DC} 81+15 \mathrm{DC} 82+15 \mathrm{DD} 81+15 \mathrm{DD} 82+15$ DE81 + 15 DE82 + 15 DF81 + 15 DF82 + 15 DG81 + 15 DG82 + 15 DH81 + 15 DH82 + 15 DI81 $+15 \mathrm{DI} 82+15 \mathrm{DJ} 81+15 \mathrm{DJ} 82 \leq 5880$

i. $15 \mathrm{DA} 91+15 \mathrm{DA} 92+15 \mathrm{DB} 91+15 \mathrm{DB} 92+15 \mathrm{DC} 91+15 \mathrm{DC} 92+15 \mathrm{DD} 91+15 \mathrm{DD} 92+15$ DE91 + 15 DE92 + 15 DF91 + 15 DF92 + 15 DG91 + 15 DG92 + 15 DH91 + 15 DH92 + 15 DI91 +15 DI92 + 15 DJ91 + 15 DJ92 $\leq 5880$

j. $15 \mathrm{DA} 101+15 \mathrm{DA} 102+15 \mathrm{DB} 101+15 \mathrm{DB} 102+15 \mathrm{DC} 101+15 \mathrm{DC} 102+15 \mathrm{DD} 101+15$ DD102 + 15 DE101 + 15 DE102 + 15 DF101 + 15 DF102 + 15 DG101 + 15 DG102 + 15 DH101 $+15 \mathrm{DH} 102+15 \mathrm{DI} 101+15 \mathrm{DI} 102+15 \mathrm{DJ} 101+15 \mathrm{DJ} 102 \leq 5880$

k. $15 \mathrm{DA} 111+15 \mathrm{DA} 112$ + $15 \mathrm{DB} 111+15 \mathrm{DB} 112+15 \mathrm{DC} 111+15 \mathrm{DC} 112+15 \mathrm{DD} 111+15$ DD112 + 15 DE111 + 15 DE112 + 15 DF111 + 15 DF112 + 15 DG111 + 15 DG112 + 15 DH111 +15 DH112 + 15 DI111 + 15 DI112 + 15 DJ111 + 15 DJ112 $\leq 5880$

1. $15 \mathrm{DA} 121+15 \mathrm{DA} 122+5 \mathrm{DB} 121+15 \mathrm{DB} 122+15 \mathrm{DC} 121+15 \mathrm{DC} 122+15 \mathrm{DD} 121+15$ DD122 + 15 DE121 + 15 DE122 + 15 DF121 + 15 DF122 + 20 DG121 + 15 DG122 + 15 DH121 + 15 DH122 + 15 DI121 + 15 DI122 + 15 DJ121 + 15 DJ122 $\leq 5880$

\section{Hasil Nilai Optimasi}

Berdasarkan hasil pengolahan data yang didapat dari program LINGO, didapat total biaya penyewaan Dump Truck sebesar Rp 3.183.989.000,- selama 12 minggu. Hasil optimasi jumlah kendaraan yang dibutuhkan selama 12 minggu adalah sebagai berikut :

1. Minggu ke - 1

Jumlah Dump Truck yang dibutuhkan dari perusahaan A $20 \mathrm{~m} 3=25$

Jumlah Dump Truck yang dibutuhkan dari perusahaan A 24 m3 = 116 
Jumlah Dump Truck yang dibutuhkan dari perusahaan B $24 \mathrm{~m} 3=35$ Jumlah Dump Truck yang dibutuhkan dari perusahaan G 24 m3 $=90$ Jumlah Dump Truck yang dibutuhkan dari perusahaan H 24 m3 = 4 Jumlah Dump Truck yang dibutuhkan dari perusahaan I $24 \mathrm{~m} 3=2$

2. Minggu ke - 2

Jumlah Dump Truck yang dibutuhkan dari perusahaan A $20 \mathrm{~m} 3=19$

Jumlah Dump Truck yang dibutuhkan dari perusahaan A $24 \mathrm{~m} 3=105$

Jumlah Dump Truck yang dibutuhkan dari perusahaan B $24 \mathrm{~m} 3=46$ Jumlah Dump Truck yang dibutuhkan dari perusahaan C $24 \mathrm{~m} 3=31$ Jumlah Dump Truck yang dibutuhkan dari perusahaan F 24 m3 = 18 Jumlah Dump Truck yang dibutuhkan dari perusahaan G 24 m3 $=32$ Jumlah Dump Truck yang dibutuhkan dari perusahaan H 24 m3 = 14 Jumlah Dump Truck yang dibutuhkan dari perusahaan I $24 \mathrm{~m} 3=1$ Jumlah Dump Truck yang dibutuhkan dari perusahaan J 24 m3 = 5

3. Minggu ke - 3

Jumlah Dump Truck yang dibutuhkan dari perusahaan A $20 \mathrm{~m} 3=54$ Jumlah Dump Truck yang dibutuhkan dari perusahaan A $24 \mathrm{~m} 3=67$ Jumlah Dump Truck yang dibutuhkan dari perusahaan C $24 \mathrm{~m} 3=8$ Jumlah Dump Truck yang dibutuhkan dari perusahaan G 24 m3 $=4$ Jumlah Dump Truck yang dibutuhkan dari perusahaan H 24 m3 = 10

4. Minggu ke - 4

Jumlah Dump Truck yang dibutuhkan dari perusahaan A $20 \mathrm{~m} 3=73$ Jumlah Dump Truck yang dibutuhkan dari perusahaan A $24 \mathrm{~m} 3=77$ Jumlah Dump Truck yang dibutuhkan dari perusahaan B 20 m3 $=4$ Jumlah Dump Truck yang dibutuhkan dari perusahaan B $24 \mathrm{~m} 3=24$ Jumlah Dump Truck yang dibutuhkan dari perusahaan G 24 m3 = 4

5. Minggu ke - 5 Jumlah Dump Truck yang dibutuhkan dari perusahaan A $20 \mathrm{~m} 3=31$ Jumlah Dump Truck yang dibutuhkan dari perusahaan A 24 m3 = 162 Jumlah Dump Truck yang dibutuhkan dari perusahaan B 24 m3 = 69 Jumlah Dump Truck yang dibutuhkan dari perusahaan G 24 m3 = 11

6. Minggu ke - 6 Jumlah Dump Truck yang dibutuhkan dari perusahaan A 20 m3 = 144 Jumlah Dump Truck yang dibutuhkan dari perusahaan A 24 m3 $=97$ Jumlah Dump Truck yang dibutuhkan dari perusahaan B 24 m3 = 9

7. Minggu ke - 7 Jumlah Dump Truck yang dibutuhkan dari perusahaan A 20 m3 $=126$ Jumlah Dump Truck yang dibutuhkan dari perusahaan A $24 \mathrm{~m} 3=52$ Jumlah Dump Truck yang dibutuhkan dari perusahaan G $24 \mathrm{~m} 3=22$

8. Minggu ke - 8 Jumlah Dump Truck yang dibutuhkan dari perusahaan A $20 \mathrm{~m} 3=158$ Jumlah Dump Truck yang dibutuhkan dari perusahaan A $24 \mathrm{~m} 3=78$ Jumlah Dump Truck yang dibutuhkan dari perusahaan G 24 m3 = 35

9. Minggu ke - 9 Jumlah Dump Truck yang dibutuhkan dari perusahaan A 20 m3 $=187$ Jumlah Dump Truck yang dibutuhkan dari perusahaan A $24 \mathrm{~m} 3=100$ Jumlah Dump Truck yang dibutuhkan dari perusahaan D $24 \mathrm{~m} 3=9$ Jumlah Dump Truck yang dibutuhkan dari perusahaan G $24 \mathrm{~m} 3=89$

10. Minggu ke - 10

Jumlah Dump Truck yang dibutuhkan dari perusahaan A $20 \mathrm{~m} 3=186$ Jumlah Dump Truck yang dibutuhkan dari perusahaan A $24 \mathrm{~m} 3=97$ Jumlah Dump Truck yang dibutuhkan dari perusahaan D $24 \mathrm{~m} 3=61$ Jumlah Dump Truck yang dibutuhkan dari perusahaan E 24 m3 = 6 Jumlah Dump Truck yang dibutuhkan dari perusahaan G 24 m3 = 35 
11. Minggu ke - 11

Jumlah Dump Truck yang dibutuhkan dari perusahaan A $20 \mathrm{~m} 3=232$

Jumlah Dump Truck yang dibutuhkan dari perusahaan A $24 \mathrm{~m} 3=158$

Jumlah Dump Truck yang dibutuhkan dari perusahaan G 24 m3 = 2

12. Minggu ke - 12

Jumlah Dump Truck yang dibutuhkan dari perusahaan A 20 m3 = 214

Jumlah Dump Truck yang dibutuhkan dari perusahaan A 24 m3 = 76

Jumlah Dump Truck yang dibutuhkan dari perusahaan B $20 \mathrm{~m} 3=5$

Jumlah Dump Truck yang dibutuhkan dari perusahaan B $24 \mathrm{~m} 3=84$

Jumlah Dump Truck yang dibutuhkan dari perusahaan G 24 m3 = 13

\section{KESIMPULAN}

Dalam penelitian ini, kesimpulan yang dapat diambil adalah sebagai berikut:

1. Berdasarkan hasil dari perhitungan program linear programming, didapat biaya yang harus dikeluarkan selama 3 bulan adalah sebesar Rp 3.183.989.000,-. Dengan menggunakan metode linear programming, lebih didahulukan Dump Truck yang berkapasitas besar walaupun berharga mahal dibandingkan yang berkapasitas kecil.

2. Dari hasil dari program LINGO, didapat jumlah kendaraan total selama 12 minggu sebagai berikut :
a. Total kendaraan minggu ke $-1: 272$
b. Total kendaraan minggu ke $-2: 271$
c. Total kendaraan minggu ke $-3: 143$
d. Total kendaraan minggu ke $-4: 182$
e. Total kendaraan minggu ke $-5: 273$
f. Total kendaraan minggu ke $-6: 250$
g. Total kendaraan minggu ke $-7: 200$
h. Total kendaraan minggu ke $-8: 271$
i. Total kendaraan minggu ke $-9: 374$
j. Total kendaraan minggu ke $-10: 385$
k. Total kendaraan minggu ke $-11: 392$
1. Total kendaraan minggu ke - $12: 392$

3. Berdasarkan hasil perhitungan dengan menggunakan metode Linear Programming, didapatkan biaya yang lebih efisien dibandingkan cara memesan secara aktual di lapangan.

\section{DAFTAR PUSTAKA}

Assauri, S. 1980. Aljabar Linear Dasar Ekonometri. Bina Pustaka.

Beliana, A.M. Kusnedar, J. dan Wardani, M. 2010. Aplikasi Pencatatan Pemesanan Dump Truck Studi Kasus CV Robery Jaya Abadi.

Garg, K. T. N. 2008. Lecture Notes : Linear Programming and Duality Theorem. Indian Institute of Tehcnology Delhi.

Kholil, A. 2012. Alat Berat. Remaja Rosdakarya.

Maulidawati, G. 2014. Alat Berat Dump Truck. Politeknik Negeri Bandung.

Rostiyanti, S.F. 2008. Alat Berat Untuk Proses Konstruksi. Vol II. Rineka Cipta, Jakarta.

Taylor III, B.W. 2013. Introduction to Management Science $11^{\text {th }}$ edition, Virginia Polytechnic Institute and State University, Virginia.

Van Den Broek, R 2017. Lecture Notes on Integer Linear Programming. Utrecht University, Netherland 